\title{
Change in Morphology of Polyhydroxyamide, Polybenzoxazole and Carbon Particles by Thermal Treatments
}

\author{
Yayoi Yoshioka* \\ Technology Research Institute of Osaka Prefecture, 2-7-1 Ayumino Izumi Osaka 594-1157, Japan
}

\begin{abstract}
Polyhydroxyamide particles consisting of 4,4'-diamino-3,3'-dihydroxybiphenyl and $m$-phthalyl chloride were prepared by a precipitation polymerization method. The particles were porous spherical particles with an average diameter of ca. $1 \mu \mathrm{m}$. And the polyhydroxyamide particles were transformed into polybenzoxazole particles through the ringclosing reactions by the thermal treatment at $360{ }^{\circ} \mathrm{C}$ for $3 \mathrm{~h}$. The polybenzoxazole particles were the rugged spherical particles, but remained unchanged in the size. The thermal decoposition temperature at $5 \mathrm{wt} \%$ loss was estiamted to be 607 ${ }^{\circ} \mathrm{C}$. Also, the degrees of crystallinity for the polyhydroxyamide and polybenzoxazole particles were high. Further, the polybenzoxazole particles were transformed into carbon particles by the thermal treatment up to $1000{ }^{\circ} \mathrm{C}$. The morphology changed from rugged surface to smooth surface. However, the diameter was almost kept. Thus, the submicron-sized polyhydroxyamide, polybenzoxazole and carbon particles obtained were found to change the morphology and property by thermal treatments.
\end{abstract}

Keywords: Carbon particle, morphology, polybenzoxazole, polyhydroxyamide, property, submicron-size, thermal treatments.

\section{INTRODUCTION}

Submicron-sized polymer particles have received much attention for practical applications such as medical carriers, chromatographic carriers, material modifiers and coating agents [1-5]. The morphology of the particles have significant influences on the separation ability and insulation characteristics and so on the products as it is closely correlated with the surface area and the porosity. Also, unique and excellent characterisitic features and functions are required to satisfy novel applications. Thus, it is important and useful to create submicron-sized novel polymer particles and control the morphology and characterisitic features.

Polyhydroxyamide (PHA) is aromatic polyamide with hydroxyl groups and a precursor of polybenzoxazole (PBO). It has excellent mechanical property and solvent resistance [6-10]. Also, the hydroxyl groups have a high affinity for water and induce an interaction between molecular chains. Thus, it is thought that PHA can be used for high functional particles by designing the structure. On the other hand, PBO has excellent thermal and mechanical properties and solvent and flame resistances, which are mainly used in fiber form [10-13]. In particular, PBO fibers show the highest tensile strength and modulus among all the commercial polymer fibers. Thus, they have been applied for flack jacket and reinforcement material. However, it is difficult to fabricate PHA and PBO particles in a secondary process because of excellent mechanical property and solvent resistance. Thus,

*Address correspondence to this author at the Technology Research Institute of Osaka Prefecture, 2-7-1 Ayumino Izumi Osaka 594-1157, Japan; Tel: +81-725-51-2681; Fax: +81-725-51-2699;

E-mail: yoshioka@tri.pref.osaka.jp submicron-sized PHA and PBO particles have not been previously reported. Therefore, the particles are expected to create novel and specific applications. Meanwhile, carbon materials have excellent electrical property and thermal conductivity. Thus, submicron-sized carbon particles are also expected to be used for specific and high performance applications. However, it is not so easy to obtain submicronsized carbon spherical particles, because in many cases the spherical particles are transformed into the formless materials by the thermal treatment.

We have previously established the precipitation polymerization method using ultrasonic irradiation to prepare some types of nano- and submicron-sized aromatic polyamide particles $[14,15]$. Recently, submicron-sized aromatic polyamide with functional groups, polyhydroxyamide (PHA), particles were obtained. And they were transformed into $\mathrm{PBO}$ and carbon particles by thermal treatments. The three types of particles were almost the same in the size, but were different in the morphology. Thus, in this paper the morphologies and characteristic features of the PHA, PBO and carbon particles obtained by thermal treatments were reported.

\section{MATERIALS AND METHODS}

4,4'-Diamino-3,3'-dihydroxybiphenyl and $m$-phthalyl chloride were purchased from Tokyo Kasei Co., Japan. The reaction solvent acetone was purchased from Kishida Chemical Co., Ltd., Japan. These compounds and solvent were used as received without any further purification.

\subsection{Preparation of Polyhydroxyamide Particles}

4,4'-Diamino-3,3'-dihydroxybiphenyl (0.0005 mol) and $m$-phthalyl chloride $(0.0005 \mathrm{~mol})$ were dissolved in $50 \mathrm{ml}$ 
acetone, respectively. $5 \mathrm{ml}$ distilled water was added to the $50 \mathrm{ml} \mathrm{4,4'-diamino-3,3'-dihydroxybiphenyl} \mathrm{solution,} \mathrm{and}$ then the entire $m$-phthalyl chloride solution was added at once. The solution was subjected to ultrasonic irradiation at $28 \mathrm{KHz}$ in a water bath while mixing for a period of $30 \mathrm{~min}$. The product was extracted by centrifugal separation and washed five times with acetone and water to remove any unreacted monomer. The sample was dried in a vacuum oven at $100{ }^{\circ} \mathrm{C}$ for $2 \mathrm{~h}$ and room temperature for $12 \mathrm{~h}$.

\subsection{Preparation of Polybenzoxazole and Carbon Particles}

For polybenzoxazole particles, polyhydroxyamide particles were kept at $100{ }^{\circ} \mathrm{C}$ for $1 \mathrm{~h}$ and then heated up to $360{ }^{\circ} \mathrm{C}$ at a rate of $10{ }^{\circ} \mathrm{C} / \mathrm{min}$, followed by keeping for $3 \mathrm{~h}$. Meanwhile, for carbon particles, polybenzoxazole particles were kept at $100{ }^{\circ} \mathrm{C}$ for $1 \mathrm{~h}$ and then heated up to $1000{ }^{\circ} \mathrm{C}$ at a rate of $10{ }^{\circ} \mathrm{C} / \mathrm{min}$. These thermal treatments were performed under a nitrogen atmosphere using the TG/DTA analyzer.

\subsection{Characterization}

Infrared spectra were measured using a PerkinElmer Spectrum One infrared spectrometer (PerkinElmer Ltd., USA) in $\mathrm{KBr}$ tablets at a resolution of $4 \mathrm{~cm}^{-1}$. Thermal treatments and TG/DTA measurements were carried in a nitrogen atmosphere using a SII Nano Technology TG/DTA 6300 analyzer (SII Nano Technology Inc., Japan). The particles obtained were sputtered with a gold coating, and their morphologies were investigated using a Hitachi FeSEM S-4700 scanning electron microscope (SEM) (Hitachi Ltd., Japan). X-ray diffraction profiles were obtained using a Rigaku RINT-2500 X-ray diffractometer (Rigaku Ltd., Japan) with graphite monochromatized $\mathrm{Cu}-\mathrm{K} \alpha$ radiation and a scan speed of $1 \% \mathrm{~min}$.

\section{RESULTS AND DISCUSSION}

\subsection{Thermal Treatment and Chemical Structure}

The curve a in Fig. (1) shows the infrared spectrum of the sample in the region of $450-4000 \mathrm{~cm}^{-1}$. For the sample, characteristic bands attributed to polyamide were observed: for example, $3215 \mathrm{~cm}^{-1}$ [amide A (N-H stretching mode)], $1650 \mathrm{~cm}^{-1}$ [amide I $(\mathrm{C}=\mathrm{O}$ stretching mode $)$, and $1517 \mathrm{~cm}^{-1}$ [amide II (coupling of $\mathrm{C}-\mathrm{N}$ stretching and $\mathrm{N}-\mathrm{H}$ in-plane bending modes)][16]. In addition, bands were detected at $3400 \mathrm{~cm}^{-1}$ and $1408 \mathrm{~cm}^{-1}$, corresponding to the $\mathrm{O}-\mathrm{H}$ stretching mode and the $\mathrm{C}-\mathrm{O}-\mathrm{H}$ bending mode of hydroxyl groups $(-\mathrm{OH})$, respectively [17]. Thus, the sample obtained was determined to consist of aromatic polyamide with hydroxyl groups, polyhydroxyamide (PHA). The reaction for the precipitation polymerization is shown in Scheme (1a) and the sample obtained is noted as PHA.

Fig. (2a) shows the thermogravimetric (TG) and differential thermal analyses (DTA) curves of the PHA sample in the temperature region of $100-1000{ }^{\circ} \mathrm{C}$. The PHA sample was kept at $100{ }^{\circ} \mathrm{C}$ for $1 \mathrm{~h}$ prior to a measurement and then measured at a rate of $10{ }^{\circ} \mathrm{C} / \mathrm{min}$ under a nitrogen atmosphere. The TG curve decreased gradually in the temperature region of $140-360{ }^{\circ} \mathrm{C}$ and further changed significantly at ca. $600{ }^{\circ} \mathrm{C}$. Meanwhile, The DTA curve showed a strong endothermic peak at $315{ }^{\circ} \mathrm{C}$ and a weak endothermic peak at $590{ }^{\circ} \mathrm{C}$. It is thought that the decrease of the TG in the temperature region of $140-360{ }^{\circ} \mathrm{C}$ is derived from the evaporation of $\mathrm{H}_{2} \mathrm{O}$ generated in the ring-closing reactions as shown in Scheme (1b) [18]. Also, the ratio of weight loss estimated by the TG curve, $11 \%$, was in good agreement with the theoretical value. Based on the result, the PHA sample was heated at $360{ }^{\circ} \mathrm{C}$ for $3 \mathrm{~h}$ under a nitrogen atmosphere to complete the ring-closing reactions. Fig. (2b) shows the TG and DTA curves of the sample obtained after the thermal treatment. They showed the changes similar to those of the PHA sample at ca. $600{ }^{\circ} \mathrm{C}$. The temperature is thought to be correlated with the thermal decomposition $[6,7]$. Thus, the thermal decomposition temperatures at 5 wt $\%$ loss and at $10 \mathrm{wt} \%$ loss were estimated to be $607{ }^{\circ} \mathrm{C}$ and $632{ }^{\circ} \mathrm{C}$, respectively, indicating excellent thermal resistance $[12,19]$. Meanwhile, the change in the temperature region of $140-360{ }^{\circ} \mathrm{C}$ was not detected for the TG and DTA curves. It has been previously reported that the endothermic enthalpies of the peak at $315{ }^{\circ} \mathrm{C}$ decreased as the number ratios of the ring-closing increased [6]. Also, the flat plateau in $\mathrm{TG}$ curve indicates that the $\mathrm{H}_{2} \mathrm{O}$ was not generated. Thus,

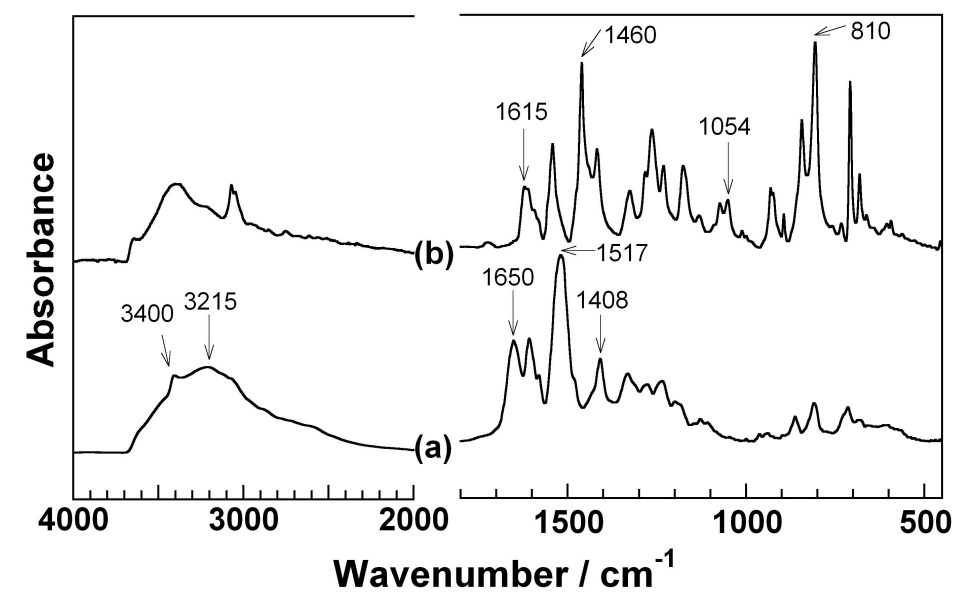

Fig. (1). Infrared spectra in the region $450-4000 \mathrm{~cm}^{-1}$ of: (a) PHA and (b) PBO particles. 


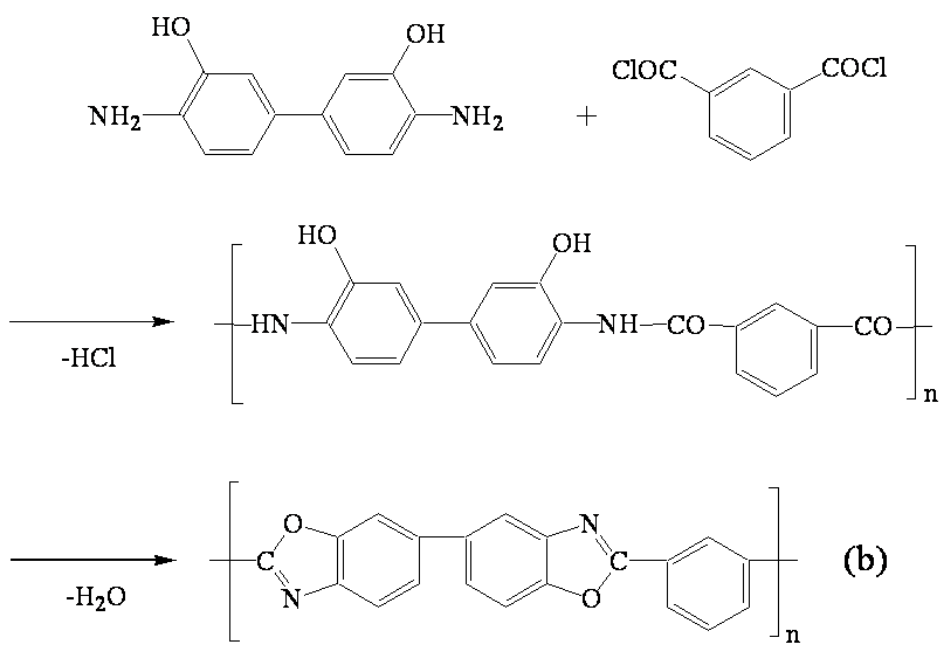

Scheme 1. Reactions; (a) from monomers to polyhydroxyamide and (b) from polyhydroxyamide to polybenzoxazole.

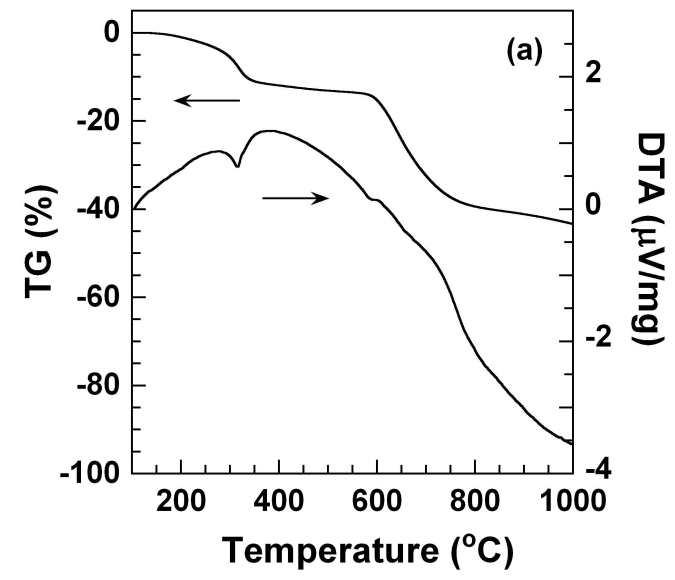

Fig. (2). Thermal diagrams of: (a) PHA and (b) PBO particles.

it is concluded that the ring-closing reactions did not occur because they completed perfectly by the previous thermal treatment.

The curve b in Fig. (1) shows the infrared spectrum of the sample obtained after the thermal treatment at $360{ }^{\circ} \mathrm{C}$ for $3 \mathrm{~h}$. Characteristic bands attributed to benzoxazole rings appeared at $1615 \mathrm{~cm}^{-1}, 1460 \mathrm{~cm}^{-1}$ and $1054,810 \mathrm{~cm}^{-1}$ $[12,13,20,21]$. On the other hand, the amide I band at $1650 \mathrm{~cm}^{-1}$ detected for the PHA sample disappeared. Based on the TG/DTA and IR results, it is thought that the PHA sample changed to polybenzoxazole completely through the ring-closing reactions (Scheme 1b). The product obtained after the TG/DTA measurement up to $1000{ }^{\circ} \mathrm{C}$ was confirmed to be carbon by the infrared spectrum (not shown).

In the following section, the sample obtained by heating the PHA sample at $360{ }^{\circ} \mathrm{C}$ for $3 \mathrm{~h}$ is noted as $\mathrm{PBO}$ and the product obtained after the TG/DTA measurement up to $1000{ }^{\circ} \mathrm{C}$ (Fig. 2b) is noted as carbon.

\subsection{Morphology}

Fig. (3 a-f) show SEM images of the PHA, PBO, carbon samples, respectively. All the samples were spherical

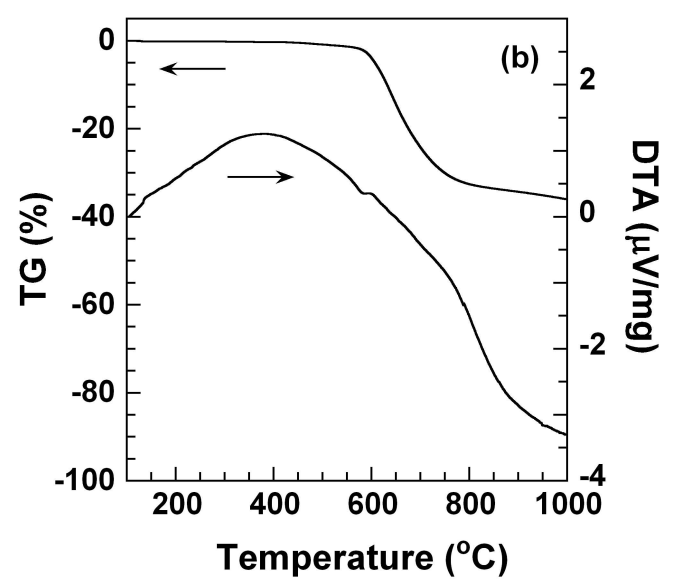

particles with average diameters of ca. $1 \mu \mathrm{m}$. The diameters were almost kept and the new connection between the particles generated by thermal treatments was not observed. On the other hand, the surface morphology changed significantly. That is, the porous PHA particles (Fig. 3 a and d) were transformed into the smooth carbon particles (Fig. 3 c and f) via the rugged PBO particles (Fig. 3 b and e). It is speculated that the pore on the surface decreased gradually in the size and then disappeared during the thermal treatments. Although the details about the morphology inside the particle and the formation mechanism have not been clarified yet, they will be revealed in the near future. Thus, the surface morphology was found to change by thermal treatments.

\subsection{Degree of Crystallinity}

Fig. (4 a-c) show X-ray diffraction patterns of the PHA, PBO and carbon particles. In the pattern for the PHA particles two sharp peaks at $2 \theta=15^{\circ}$ and $25^{\circ}$ were observed [6]. On the other hand, in the pattern for the PBO particles, some new peaks appeared except the two sharp peaks detected at the same positions for the PHA particles. It has been previously reported that the peak at $2 \theta=15^{\circ}$ is corresponding to (200) reflection and the splitting peaks at $2 \theta=25$ and $26^{\circ}$ are corresponding to (110) and $\left(\begin{array}{lll}1 & 1 & 0\end{array}\right)$ 

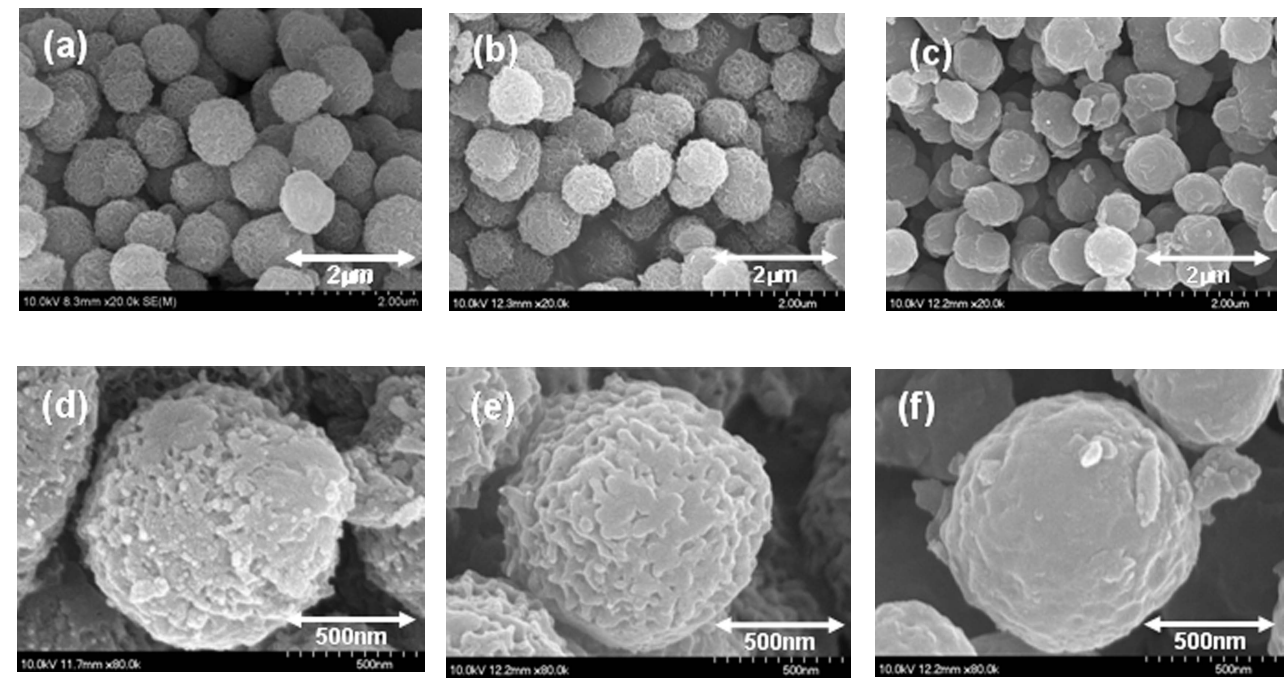

Fig. (3). SEM images of: (a) PHA, (b) PBO and (c) carbon particles and enlarged SEM images of: (d) PHA, (e) PBO and (f) carbon particles.

reflections [11]. Thus, it is speculated that the splitting peaks are originated from the change in the crystal structure result by the transformation from PHA to PBO. However, all the new peaks detected can not be assigned at the present stage. An additional X-ray structure analysis will be required for the detail assignment. Based on these sharp peaks, the PHA and $\mathrm{PBO}$ particles were found to show high degrees of crystallinity [22].

Meanwhile, in the pattern for the carbon particles one broad peak was observed. Thus, the carbon particles were found to be amorphous [19].

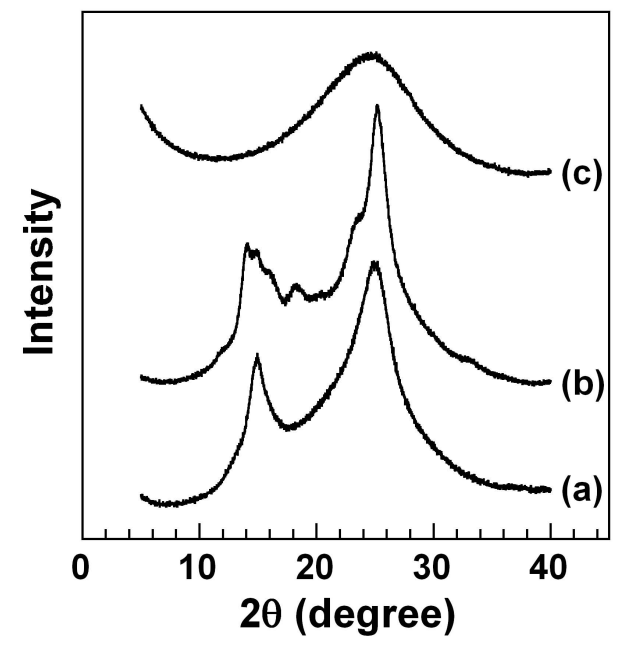

Fig. (4). X-ray diffraction patterns of: (a) PHA, (b) PBO and (c) carbon particles.

\section{CONCLUSION}

Polyhydroxyamide (PHA) particles have been prepared from 4,4'-diamino-3,3'-dihydroxybiphenyl and $m$-phthalyl chloride by the precipitation polymerization method. The particles were porous spherical particles with an average diameter of ca. $1 \mu \mathrm{m}$. And the PHA particles were transformed into polybenzoxazole (PBO) particles through the ring-closing reactions by the thermal treatment at $360{ }^{\circ} \mathrm{C}$ for $3 \mathrm{~h}$. The PBO particles were the rugged spherical particles, which diameter was almost kept. The thermal decoposition temperature of the PBO particles was estiamted to be $607{ }^{\circ} \mathrm{C}$ at $5 \mathrm{wt} \%$ loss, indicating excellent thermal resistance. The degrees of crystallinity for the PHA and PBO particles were high. Further, the rugged $\mathrm{PBO}$ particles were transformed into the smooth carbon particles by the thermal treatment up to $1000{ }^{\circ} \mathrm{C}$, which size was almost kept. Thus, the submicron-sized PHA, PBO and carbon particles obtained were found to change the morphology and property by thermal treatments. The change in the morphology is effective for controlling the surface area and the porosity of the particles. The transformation from the porous particles into the non-porous particles is expected to be available for the preparation of the particles composited with other materials.

\section{CONFLICT OF INTEREST}

Declared none.

\section{ACKNOWLEDGEMENT}

Declared none.

\section{REFERENCES}

[1] Ugelstad J, Mfutakamba HR, Mork PC, et al. Preparation and application of monodisperse polymer particles. J Polym Sci Polym Symp 1985; 72: 225-40.

[2] Koyama T, Terauchi K. Synthesis and application of boronic acdimmobilized porous polymer particles: a novel packing for highperformance liquid affinity chromatography. J Chromatogr B 1996; 679: 31-40.

[3] Eldin MSM, Schroen CGPH, Janssen AEM, Mita DG, Tramper J. Immobilization of penicillin $G$ acylase onto chemically grafted nylon particles. J Mol Catal B Enzym 2000; 10: 445-51.

[4] Akagi T, Kaneko T, Kida T, Akashi M. Preparation and characterization of biogegradable nanoparticles based on $\operatorname{poly}(\gamma-$ glutamic acid) with L-phenylalanine as a protein carrier. J Control Release 2005; 108: 226-36. 
[5] Bhaw-Luximon A, Meeram LM, Jugdawa Y, Helbert W, Jhurry D. Oligoararose-g-polycaprolactone loaded nanoparticles for drug delivery applications. Polym Chem 2011; 2: 77-9.

[6] Chang J-H, Park KM, Lee IC. Thermal cyclodehydration of aromatic precursor polymers to polybenzoxazole and polyimide; their thermal and mechanical properties. Polym Bul 2000; 44: 63-9.

[7] Chang J-H. Characterization of two precursor polyblends: polyhydroxyamide and poly(amic acid). Polym Eng Sci 2000; 40: 320-9.

[8] Park SK, Cho SH, Farris RJ. Dry-jet spinning of polyhydroxyamide fibers. Fiber Polym 2000; 1: 92-6.

[9] Yoo E-S, Gavrin AJ, Farris RJ, Coughlin EB. Synthesis and characterization of the polyhydroxyamide/polymethoxyamide family of polymers. High Perform Polym 2003; 15: 519-35.

[10] Hsu SL-C. Lin K-S, Wang C. Preparation of polybenzoxazole fibers via electrospinning and postspun thermal cyclization of polyhydroxyamide. J Polym Sci Part A: Polym Chem 2008; 46: 8159-69.

[11] Klop EA, Lammers M. XRD study of the new rigid-rod polymer fibre PIPD. Polymer 1998; 39: 5987-98.

[12] Tullos GL, Mathias LJ. Unexpected thermal conversion of hydroxyl-containing polyimides to polybenzoxazoles. Polymer 1999; 40: 3463-8.

[13] Chen K, Anthamatten M, Harding DR. Vapor deposition and curing of polybenzoxazole precursors. Macromolecules 2006; 39: 7561-5.

[14] Yoshioka Y, Asao K, Yamamoto K, Tachi H. Preparation of micron-sized aromatic polyamide particles using ultrasonic irradiation. Colloid Polym Sci 2007; 285: 535-41.
[15] Yoshioka Y, Asao K, Yamamoto K, Tachi H. Preparation and characterization of nanoscale aromatic polyamide particles. Polymer 2007; 48: 2214-20.

[16] Socrates G. In: Infrared and raman characteristic group frequencies. Chichester: John Wiley \& Sons 1991; pp.143-8.

[17] Lin-Vien D, Colthup NB, Fateley WG, Grasselli JG. In: The handbook of infrared and raman characteristic frequencies of organic molecules, $3^{\text {rd }}$ ed. California: Academic Press: 1991; pp. 45-59.

[18] Wang H, Liu S, Chung T-S, Chen H, Jean Y-C, Pramoda KP. The evolution of poly(hydroxyamide amic acid) to poly(benzoxazole) via stepwise thermal cyclization: Structural changes and gas transport properties. Polymer 2011; 52: 5127-38.

[19] Chang J-H, Park KM, Lee SM, Oh JB. Two step thermal conversion from poly(amic acid) to polybenzoxazole via polyimide: their thermal and mechanical properties. J Polym Sci Part B: Polym Phys 2000; 38: 2537-45.

[20] Isayeva VA, Chernikhov AY, Korshak VV, Noskova MP Guryanova VV. Investigation of the cyclodehydration of a poly-ooxyamide based on 3,3'-dioxy-4,4'-diamonodiphenylmethane and isophthalic acid dichloride. Polymer Sci USSR 1979; 21: 3053-61.

[21] Likhatchev D, Gutierrez-Wing C, Kardash I, Vera-Graziano R. Soluble aromatic polyimides based on 2,2-bis(3-amino-4hydroxyphenyl)hexafluoropropane: synthesis and properties. J Appl Polym Sci 1996; 59: 725-35.

[22] Krause SJ; Haddock TB, Vezie DL, et al. Morphology and properties of rigid-rod poly(p-phenylene bezobisoxazole)(PBO) and stiff-chain poly(2,5(6)-benzoxazole)(ABPBO) fibres. Polymer 1988; 29: 1354-64.

(C) Yayoi Yoshioka; Licensee Bentham Open.

This is an open access article licensed under the terms of the Creative Commons Attribution Non-Commercial License (http://creativecommons.org/licenses/by-nc/3.0/) which permits unrestricted, non-commercial use, distribution and reproduction in any medium, provided the work is properly cited. 